\title{
Review
}

\section{Life, emergent: The social in the afterlives of violence}

\author{
Yasmeen Arif \\ University of Minnesota Press, Minneapolis, 2016, 212 pp. + notes, \\ ISBN: 9781452953076
}

Contemporary Political Theory (2019) 18, S75-S77. https://doi.org/10.1057/s41296017-0176-1; published online 13 November 2017

This is an interesting book that makes many thought-provoking claims related to theories of biopolitics and the role of affect in the constitution of the social. Drawing on ethnographic methods, the author explores a series of case studies of what are dubbed the 'afterlife' of catastrophic mass violence, as in war and various other forms of communal and ethnic conflict. She finds that the particular form of pathos that emerges after such violence creates a system of 'emotional relationalities' that are productive of the forms of life (or bios) that live on in the afterlife of those incidents (p. 20). Pathos is defined as collective 'witnessing and alleviating' of suffering (p. 20). The concept is used to define a system of affective relations that emerge in these afterlives, structuring the kinds of subjectivities and identities that develop among the survivors. The theoretical resources invoked to establish this framework are many, but centrally the author is indebted to Michel Foucault, Giorgio Agamben, Roberto Esposito, and Gilles Deleuze. Foucault's notion of a dispositif is particularly important as in the final pages of the book the author reveals that what has been at stake in each chapter is an instance of the 'event-afterlife' paradigm/dispositif. For Foucault, a dispositif defines an ensemble of heterogeneous elements, such as institutions, urban designs, laws, regulatory decisions, political statements, moral and ethical ideas, that are related to each other through a certain system of relations defined by discourses of knowledge/ power. The unique feature of the event-afterlife dispositif that this book puts forward is the idea that the system of relations that connect the elements in a dispositif may not only relate to knowledge/power, but also to collective affect.

Each chapter offers a case study of an historical case of mass violence, the forms of collective pathos that followed, and how individuals and communities live on through differently negotiating the relationalities that are constituted through that pathos. An important aspect of the analysis is the idea that the way that suffering is collectively witnessed creates a set of affective relationalities that constitute the social. In this sense, each chapter presents an example of the event-afterlife

(c) 2017 Macmillan Publishers Ltd., part of Springer Nature. 1470-8914 Contemporary Political Theory Vol. 18, S2, S75-S77 www.palgrave.com/journals 
dispositif, distinguished by unique forms of pathos and bios, 'or forms of life and the social relationalities in which those forms emerge' (p. 172). Chapter one focusses on the implementation of the Special Court of Sierra Leone (SCSL) after the end of Sierra Leonean Civil War in 1999. The SCSL was unique in being the first hybrid court set up under the national jurisdiction of the government of Sierra Leone and the jurisdiction of the United Nations under international law. The mandate of the SCSL was to prosecute violations of human rights defined in international law and violations of the law of Sierra Leone. The author takes the workings of the SCSL to represent a form of collective witnessing, or as she writes, 'a particular articulation of pathos and a bios' (p. 40). The pathos lies 'in the trade between law and humanitarian sentiment', which constitutes an 'international social' (p. 40). Within this form of the social, bios includes those whose experiences are defined (or not) as crimes and constituted as 'punishable bodies' within these terms (pp. 40, 62). These forms of pathos and bios are different from those discussed in chapter three, which looks at the 'afterlife' of anti-Sikh violence that gripped Delhi in the days following the assassination of Prime Minister Indira Ghandi on 31 October 1984. In that case, gendered norms split survivor communities, which also occupied different areas of the city. For men from the Bhogal area, for example, values such as 'resilience and work ethic' that are 'emblematic' of Sikh identity become 'a resource that they draw their sustenance from' (p. 130). Arif notes that these men expressed themselves through 'an anchoring in their group identity rather than speaking of personal hardship' ( $p$. 130). In contrast, for the women who were widowed during the massacre and live in a widows' colony the suffering is 'undoubtedly private' (p. 131). Although very different, in both the case of the Sierra Leonean Civil War and the aftermath of the Sikh massacre in Delhi, the form of collective witnessing that emerged created affective relationalities that allowed new possibilities for living on, while foreclosing others. This ambivalent aspect of the event-afterlife dispositif was constant throughout the case studies. The juxtaposition of different forms of pathos in each chapter sheds light on the central role that collective witnessing plays in constituting a social after an event of catastrophic violence, and how different forms of collective witnessing are related to the subjectivities and identities that are livable within a new social, marked by that violence as well as other histories.

The most challenging aspect of the book lies in its structure, as the majority of the methodological and theoretical framing comes only in the conclusion, with an introductory chapter that touches on some of the central themes but does not make clear their import for the ensuing analysis. The author justifies this by citing a quip from Agamben on how in the human sciences, 'contrary to common opinion, a reflection on method usually follows practical application, rather than preceding it' (p. 174). While this is probably true, it is not clear that it is necessarily the best way to structure a book. In this case, the structure somewhat obscures the analysis as the central concepts are not explicitly developed in the chapters. It is only the 
conclusion that reveals the event-afterlife dispositif to be the central concept driving the analysis and, further, that it is informed by Deleuze's concept of the 'pure event'. This major component of the book's theoretical framework could have been laid out at the beginning. Considering that the ontological nature of the 'pure event' is different from that which underlies the Foucauldian conception of a dispositif, it would have been interesting to see discussion of how the two work together. Each chapter speaks to this implicitly, to varying degrees, but the discussions are not linked explicitly to the broader theoretical framework of the book.

The introduction is concerned with situating the book as a response to a supposed over-emphasis in academic literature on biopolitics on the 'negative', which is to say, the power to kill or to let die. The author argues that thinkers like Foucault and Agamben focus too much on 'how life is defined in its exposure to death' (p. 13). In contrast, the goal of the book is to focus on 'how life is constituted in the contemporary when it is exposed to life as such' (p. 14). This idea, that there is an affirmative and a negative side to biopolitics, and that Foucault focused on the latter, is indeed evident in some secondary literature. However, the characterisation is fundamentally misleading as it does not take into account the distinct but overlapping concept of biopower, which refers to power over the life of individuals and a population. In this form of power, letting die and making live are not separable, but two aspects of the same gesture. Biopolitics can be distinguished from biopower, in that the former refers to the historical condition in which the population is also taken up as an object of political strategy through techniques of biopower. Distinguishing between biopower and biopolitics would have provided a more nuanced understanding of the negative/affirmative relation that the author is responding to, while still providing conceptual resources to account for the creation of bios in the afterlife of catastrophic violence.

Amy Swiffen

Concordia University, Montreal, QC H3G 1M8, Canada amy.swiffen@concordia.ca

(ㄷ) 2017 Macmillan Publishers Ltd., part of Springer Nature. 1470-8914 Contemporary Political Theory Vol. 18, S2, S75-S77 S77 